\title{
CCNI2 promotes the progression of human gastric cancer through HDGF
}

\author{
Wenchao Chen, Yang Zhou, Gang Wu ${ }^{*}$ and Peichun Sun ${ }^{*}$
}

\begin{abstract}
Background: Gastric cancer is a highly aggressive malignant tumor with heterogeneity and is still a global health problem. The present study aimed to investigate the role of Cyclin I-like (CCNI2) in the regulation of phenotype and tumorigenesis, as well as its underlying mechanisms.

Method: The expression profile of CCNI2 in gastric cancer was determined based on The Cancer Genome Atlas (TCGA) database and immunohistochemical staining. The effects of altered CCNI2 expression on the biological phenotypes such as proliferation, clone formation, apoptosis and migration of gastric cancer cell lines BGC-823 and SGC-7901 were investigated. Mice xenograft models were established to reveal the role of CCNI2 knockdown on tumorigenesis. The potential mechanism of CCNI2 regulating gastric cancer was preliminarily determined by RNA sequencing.

Result: CCNI2 was abundantly expressed in gastric cancer and was positively correlated with pathological stage. Knockdown of CCNI2 slowed down the malignant progression of gastric cancer by inhibiting tumor cell proliferation, increasing the susceptibility to apoptosis and suppressing migration. Moreover, downregulation of CCNI2 attenuated the ability of gastric cancer cells to form tumors in mice. Additionally, there was an interaction between CCNI2 and transcription factor hepatoma-derived growth factor (HDGF) in SGC-7901 cells. Knockdown of CCNI2 alleviated the promoting effects of HDGF overexpression in gastric cancer cells.
\end{abstract}

Conclusions: CCNI2 promoted the progression of human gastric cancer through HDGF, which drew further interest regarding its clinical application as a potential therapeutic target.

Keywords: Gastric cancer, CCNI2, Proliferation, Apoptosis, Migration, RNA sequencing, HDGF

\section{Background}

Gastric cancer is a highly aggressive malignant tumor with heterogeneity and is still a global health problem [1]. Current statistics show that gastric cancer as the fifth most common cancer and the third most common cause of cancer death in the world [2]. In addition, the incidence of gastric cancer increased progressively with the age [3]. Unfortunately, most patients with gastric cancer are diagnosed at an advanced stage, and treatment is

*Correspondence: wugang@zzu.edu.cn; Sunpeichunyz@126.com Department of Gastrointestinal Surgery, Henan Provincial People's Hospital, Zhengzhou University People's Hospital, Henan University

People's Hospital, Zhengzhou 450003, Henan, China often ineffective [4]. To date, gastrectomy and chemotherapy are the mainly therapeutic options for gastric cancer patients, but drug resistance, either acquired or primary, is the main cause for treatment failure [5]. In view of the fact that cancer is a multi-stage disease process, characterized by the gradual development of various gene expression mutations and epigenetic alterations, precise targeted therapy has become a hotspot. Recently, targeted therapies licensed to treat gastric cancer include trastuzumab (HER2-positive patients first line), ramucirumab (anti-angiogenic second line), and nivolumab or pembrolizumab (anti-PD-1 third line) [6-9]. The heterogeneity and drug resistance of patients with gastric cancer are still key obstacles to targeted therapy. Therefore, a original author(s) and the source, provide a link to the Creative Commons licence, and indicate if changes were made. The images or other third party material in this article are included in the article's Creative Commons licence, unless indicated otherwise in a credit line to the material. If material is not included in the article's Creative Commons licence and your intended use is not permitted by statutory regulation or exceeds the permitted use, you will need to obtain permission directly from the copyright holder. To view a copy of this licence, visit http://creativecommons.org/licenses/by/4.0/. The Creative Commons Public Domain Dedication waiver (http://creativeco mmons.org/publicdomain/zero/1.0/) applies to the data made available in this article, unless otherwise stated in a credit line to the data. 
comprehensive understanding of the mechanisms of gastric cancer is required to overcome these challenges.

Cyclin-dependent kinase 5 (CDK5) exerts important roles in gene expression, cytoskeleton dynamics, signal cascade, and cell survival in a variety of cells $[10,11]$. The kinase activity of CDK5 is tightly regulated by specific activators including p35, p39, and cyclin I (CCNI). As a homolog of CCNI, CCNI2 interacts with CDK5 and activates the kinase activity of CDK5 to participate in cell cycle regulation [12]. In addition, tumor-associated cell cycle defects are often mediated by alterations in CDK5 activity. Abnormal overexpression of CDK5 can lead to genome and chromosome instability as well as accelerate cell proliferation [13]. As a result, the dysregulation of CDK5 has been implicated in various diseases, such as Alzheimer's disease (AD), amyotrophic lateral sclerosis (ALS), Parkinson's disease (PD) and cancers [10, 11, 14]. Thus, inhibition of CDK5 activity may have therapeutic effects on some human tumors [15]. Moreover, Cyclin I-like (CCNI2), a homologue of CCNI, is a novel CDK5 activator. It reported that cell cycle progression and proliferation were inhibited after knockdown of CCNI2 [16]. Recently, Lai et al., demonstrated that CCNI2 played a promoting role in the progression of colorectal cancer [17]. Accordingly, these studies point towards a potential promoting effect of CCNI2 on cancers that warrants further investigations.

Therefore, the present study investigated the role of CCNI2 in the regulation of gastric cancer on proliferation, apoptosis, migration and tumorigenesis, as well as its underlying mechanisms. In this study, CCNI2 expression levels in gastric cancer were predicted in the database and further confirmed by immunohistochemical staining. In vitro and in vivo loss-of-function assays were performed in BGC-823 and SGC-7901 cells [18] to explore the role of CCNI2 in gastric cancer. Moreover, the potential downstream mechanism of CCNI2 regulating gastric cancer was initially identified through gene microarray. Altogether, our data revealed the promotive role of CCNI2 in the progression of gastric cancer and drew further interest regarding its clinical application as a potential therapeutic target.

\section{Methods}

\section{Tissue microarray (TMA) and immunohistochemical} staining

The protocol was approved by the Institutional Ethics Committee of the Henan Provincial People's Hospital, and informed consent of all patients was obtained. The pathological specimens were collected from 150 patients with gastric cancer who underwent primary surgical resection. The patients with gastric cancer treated surgically only without co-morbidities were included in the study. Notably, normal tissues used in the TMA were collected from paracancerous tissues of gastric cancer patients. TMA sections contained tumor tissues $(\mathrm{n}=150)$ and matched normal tissues $(\mathrm{n}=150)$, which were constructed according to the methods in the literature [19]. Formalin-fixed paraffin-embedded samples were cut into $5-\mu \mathrm{m}$ sections and deparaffinized and rehydrated. Following the manufacturer's protocols, the sections were treated with diluted primary antibody against CCNI2 (1:50, Thermo Fisher Scientific, PA5-35081) at $4^{\circ} \mathrm{C}$ overnight and secondary antibody HRP goat antirabbit IgG (1:200, Beyotime, A0208) at room temperature for $30 \mathrm{~min}$. subsequently, sections were stained by $\mathrm{DAB}$ and hematoxylin at room temperature to detect the signal. The intensity of CCNI2 positive staining in TMA sections was scored as previously describe [20]. Cases showing hybrid scores of more than or equal to the median were considered as CCNI2 high expression.

\section{Cell culture condition}

Human gastric cancer cell lines, BGC-823 and SGC-7901 were purchased from Cell Bank of the Chinese Academy of Sciences (Shanghai, China), where the cell lines were authenticated by STR profiling before experiment. The cell lines were maintained in Dulbecco's modified eagle medium (DMEM) (Gibco, Thermo Fisher Scientific, USA) supplemented with $10 \%$ fetal bovine serum (Gibco), 100 units $/ \mathrm{mL}$ penicillin, and $100 \mathrm{mg} / \mathrm{mL}$ streptomycin in a $5 \% \mathrm{CO}_{2}$ humidified incubator at $37^{\circ} \mathrm{C}$.

\section{RNA interference and lentivirus transfection}

Small RNA interference specifically targeted human CCNI2 (shCCNI2) and non-specific negative control (shCtrl) was synthesized. Lentiviral vectors with green fluorescent protein (GFP) labels were purchased from Shanghai Bioscienceres (Shanghai, China). Lentivirus plasmid including shCtrl (control plasmid), shCCNI2 (CCNI2 knockdown recombinant plasmid), and HDGF (amplified lentiviral plasmid) was constructed using T4 DNA ligase (Gibco, Thermo Fisher Scientific, USA) following the manufacturer's protocols, respectively. BGC-823 and SGC-7901 cells were cultured for $24 \mathrm{~h}$ and transfected with recombinant lentivirus using Lipofectamine $^{\circledR} 2000$ (Invitrogen; Thermo Fisher Scientific, USA) at $10 \mathrm{MOI}$ (multiplicity of infection). The sequence is as follows: shCCNI2-1: 5'-TACCTGCATTGCGCC ACAATT-3', shCCNI2-2: 5'-ATCTGCGACGCCTTC GAGGAA-3', shCCNI2-3: 5'-CCTGGAAGGCGACCT GGACGA- $3^{\prime}$.

HDGF-F: 5'-GATTCTAGAGCTAGCGAATTCGCC ACC ATG CACCCG GAA GGT GGCCAATTTG-3', HDGF-R: $\quad 5^{\prime}$-TCCTTGTAGTCCATACCGGTCAGG CTCTCATGATCTCTGATGCC- $3^{\prime}$. 


\section{RNA extraction and qPCR}

Total RNA isolation from BGC-823 and SGC-7901 cell lines using Trizol reagent (Invitrogen, Carlsbad, CA, USA) following the manufacturer's protocols. The qPCR procedures were performed using the SYBR Green master mix (Thermo Fisher Scientific) as previously describe [21]. The mRNA expression of CCNI2 and HDGF was assessed by threshold cycle CT values and analyzed using $2^{\Delta \Delta \mathrm{Ct}}$ method. All samples were performed in triplicate three times and the GAPDH mean value was used to normalize gene expression. The primers for amplification of human genes were listed as Additional file 1: Table S1.

\section{Protein extraction and western blot analysis}

Preparation of whole cell lysates with protease inhibitor cocktail and phosphatase inhibitor cocktail (Roche, Alameda, CA, USA). Protein concentration was determined through BCA protein assay kit (Beyotime, Jiangsu, China). Equal amounts of protein were subjected to $10 \%$ SDS-polyacrylamide gel electrophoresis, transferred to PVDF membranes (Millipore, Danvers, MA, USA) and hybridized with corresponding primary antibody (Additional file 1: Table S2) overnight at $4{ }^{\circ} \mathrm{C}$. The PVDF membranes were washed with TBST three times and incubated with HRP-conjugated secondary antibody for $2 \mathrm{~h}$ at room temperature. Signals were visualized by chemiluminescence ECL kit (Thermo Fisher Scientific) and Odyssey Infrared scanning system (Li-Cor, Lincoln, NE, USA).

\section{Co-immunoprecipitation (Co-IP) assay}

A target protein-specific diluted primary antibody against CCNI2 or HDGF (Additional file 1: Table S2) in conjunction with protein A/G affinity beads (Santa Cruz Biotechnology) for $1 \mathrm{~h}$ at $4{ }^{\circ} \mathrm{C}$. The bead-antibody complex was suspended with protein lysate and washed with extraction buffer for 3 times. Subsequently, the immunoprecipitants were subjected to western blot.

\section{Cell proliferation assays}

BGC-823 and SGC-7901 cells were cultured in 96-well plates at a density of 2000 cells/well. After Methyl thiazolyl tetrazolium (MTT) was added to the well, the OD490 value was detected under a microplate reader (Thermo Fisher Scientific) at 1-, 2-, 3-, 4- and 5-day post cell seeding, and the growth curve was drawn to analyze the cell proliferation ability. Moreover, Celigo cell counting assay was performed to determine cell proliferation ability. The cells with GFP were identified with Celigo
(Nexcelom), photographed, counted at predetermined time and the cell growth curve was plotted.

\section{Colony formation assay}

BGC-823 and SGC-7901 cells were cultured 14 days in six-well plates at a density of 1000 cells per well. Cell colonies were washed with cold phosphate buffer brine (PBS) for 2 times, fixed with $75 \%$ ethanol, stained with $0.1 \%$ crystal violet, counted and photographed.

\section{Cell apoptosis detection}

BGC-823 and SGC-7901 cells were inoculated into sixwell plates $(2 \mathrm{~mL} /$ well $)$ cultured for 5 days. Following the manufacturer's protocols of FITC (fluorescein isothiocyanate) Annexin V apoptosis detection kit I (BD Biosciences), the cell precipitation was successively eluted with precooled D-hanks ( $\mathrm{pH}=7.2 \sim 7.4)$ and $1 \times$ binding buffer. Cell precipitates were resuspended with $200 \mu \mathrm{L}$ $1 \times$ Binding Buffer, stained with $10 \mu \mathrm{L}$ Annexin V-APC at room temperature for $15 \mathrm{~min}$ and cell apoptosis was detected by flow cytometry on a BDTM LSR II (BD Biosciences) equipped with FlowJo software (version vx 0.7) (BD Biosciences).

\section{Transwell assay}

Transwell chambers (24-well, 8-mm pore, Corning, MA, USA) were performed to estimate the BGC-823 and SGC7901 cells migration ability in $24-w e l l$ plates. The cells were digested by trypsin, resuspended into cell suspension $(80,000$ cells/well) and placed into Transwell chambers cultured for $72 \mathrm{~h}$. The medium was removed from the upper and lower compartments and $500 \mathrm{~mL}$ of $70 \%$ ethanol was placed in the lower compartment to fix the cells at room temperature for $15 \mathrm{~min}$. The non-invading cells on the upper chamber were removed, while the cells adhering to the Polycarbonate membrane was fixed with $4 \%$ precooled paraformaldehyde for $30 \mathrm{~min}$ and stained with $0.5 \%$ crystal violet for $30 \mathrm{~min}$ at room temperature. Finally, the migrated cells were photographed from five randomly selected fields under a $200 \times$ microscope.

\section{Wound-healing assay}

BGC-823 and SGC-7901 cells were cultured into 6-well plates $(100 \mu \mathrm{L} /$ well $)$ at a density of 4000 cells per well. The experimental procedures were performed as described previously [22]. Cells were washed with PBS, fixed with $3.7 \%$ paraformaldehyde (Corning) for $15 \mathrm{~min}$, stained with $1 \%$ crystal violet (Corning) for $10 \mathrm{~min}$ and viewed under a microscope for image acquisition. Cell migration distance $(\mu \mathrm{m})$ at $0 \mathrm{~h}$, and $48 \mathrm{~h}$ was quantified through Image J software (National Institutes of Health). 


\section{Mice xenograft tumor assay}

The experimental procedures performed on the mice were approved by the Ethics Committee of Henan Provincial People's Hospital and accordance with Guide for Care and Use of Laboratory animals (NIH publication number 85-23, revised at 1996). BALB/c nude specific pathogen free (SPF) mice (4 weeks, 18 to $23 \mathrm{~g}$; Lingchang biological, Shanghai) were kept in a sterile environment and fed normally. SGC-7901 cells transfected with lentivirus were digested with trypsin, injected into the right forearm of mice $\left(500 \mu \mathrm{L}, 6 \times 10^{6}\right.$ cells/mouse $)$ and divided into shCtrl $(\mathrm{n}=10)$ and shCCNI2 $(\mathrm{n}=10)$ groups. After mice were injected with tumor cells for 7 days, the tumor volume was monitored 1 to 2 times a week and calculated as follows: $\pi / 6 \times \mathrm{L} \times \mathrm{W} \times \mathrm{W}$ (L represented long diameter and $\mathrm{W}$ represented short diameter). After 26 days, the mice were anesthetized with $0.7 \%$ sodium pentobarbital $(10 \mu \mathrm{L} / \mathrm{g})$ and evaluated the intensity of tumor fluorescence imaging under the IVIS spectral imaging system (emission wavelength of $510 \mathrm{~nm}$ ). Subsequently, the mice were sacrificed by cervical dislocation, tumors were excised and weighed. Afterwards, the mice tumor tissues were subjected to immunohistochemical staining to evaluate Ki67 (1:200, Abcam, ab16667) expression levels.

\section{RNA sequencing}

RNA was purified from SGC-7901 cells transfected with shCtrl/shCCNI2 and sequenced using Affymetrix Prime View human gene chip (Affymetrix Scanner 3000 scan). According to the criteria of |Fold Change| $\geq 1.8$ and false discovery rate $(F D R) \leq 0.05$, differentially expressed genes (DEGs) were identified, and hierarchical clustering was performed. The interaction network between CCNI2 and DEGs was further analyzed based on Ingenuity Pathway Analysis (IPA).

\section{Statistical analysis}

Data were obtained from three independent experiments which were presented as the means \pm standard deviation (SD) and P value $<0.05$ was considered significant. Comparisons between different groups were analyzed with unpaired Student's $t$ test. The significance of differences between groups was assessed by GraphPad Prism V8.0 (GraphPad, CA, USA) and SPSS 20.0 (IBM, SPSS, IL, USA).

\section{Results}

\section{CCNI2 is abundantly expressed in gastric cancer}

Based on The Cancer Genome Atlas (TCGA) database of 407 gastric cancer samples for expression profile analysis, we found that the expression level of CCNI2 in tumors was significantly higher than that of normal samples (Fig. 1A). The correlation between the expression level of CCNI2 in gastric cancer tissues and clinical prognosis was analyzed (Additional file 1: Fig. S1A). Although the expression level of CCNI2 was not significantly associated with the prognosis of gastric cancer patients, the survival period of gastric cancer patients with high CCNI2 expression was short. Subsequently, we performed TMA and immunohistochemical staining on tissue samples from clinical gastric cancer patients. According to the scoring result of immunohistochemistry, greater than or equal to 4 was considered as CCNI2 high expression. High expression of CCNI2 was observed in 43 of 93 tumor tissue $(46.2 \%)$ and in 0 of 101 normal tissues (Table 1; Fig. 1B). Consistently, the representative images of immunohistochemical staining showed that the signal intensity of CCNI2 was markedly higher in tumor tissues than in normal tissues (Fig. 1C). To investigate the significance of $\mathrm{CCNI} 2$ expression in gastric cancer, we analyzed the correlations of CCNI2 levels with different clinicopathological characteristics. Based on Mann-Whitney U analysis, there was a significant positive correlation between the expression level of CCNI2 and pathological stage (Table 2). In addition, Spearman rank correlation analysis further indicated that as the malignant degree of the tumor deepened, the expression of CCNI2 increased (Table 3). Collectively, CCNI2 was abundantly expressed in gastric cancer and positively correlated with pathological stage.

\section{Downregulation of CCNI2 inhibited proliferation, promoted apoptosis and suppressed migration of gastric cancer cells}

To explore the role of CCNI2 in gastric cancer, we determined the effect of CCNI2 downregulation on tumor biological behaviors including proliferation, colony formation, apoptosis, and migration. CCNI2 shRNA (shCCNI2-1) was used in BGC-823 and SGC-7901 cells to knockdown CCNI2 expression (Additional file 1: Fig. $\mathrm{S} 1 \mathrm{~B})$. The knockdown efficiency of CCNI2 was assessed at both mRNA and protein levels, indicating that CCNI2 expression was downregulated in BGC-823 and SGC7901 cells (Additional file 1: Fig. S1C). We first determined the effect of CCNI2 on tumor cell proliferation, suggesting that decrease of CCNI2 expression resulted in reduced proliferation of gastric cancer cells BGC823 and SGC-7901 (Fig. 2A). Gastric cancer cells with reduced $\mathrm{CCNI} 2$ expression produced smaller colonies and reduced numbers (Fig. 2B). Moreover, apoptosis rate in the shCCNI2 group was higher than that in the shCtrl group, indicating that CCNI2 knockdown increased the susceptibility to apoptosis (Fig. 2C). Furthermore, knockdown of CCNI2 in BGC-823 cells upregulated the expression of Bad, BID, and cytoC. On the contrary, the expression levels of HSP60, IGF-II, and sTNF-R1 were 
A
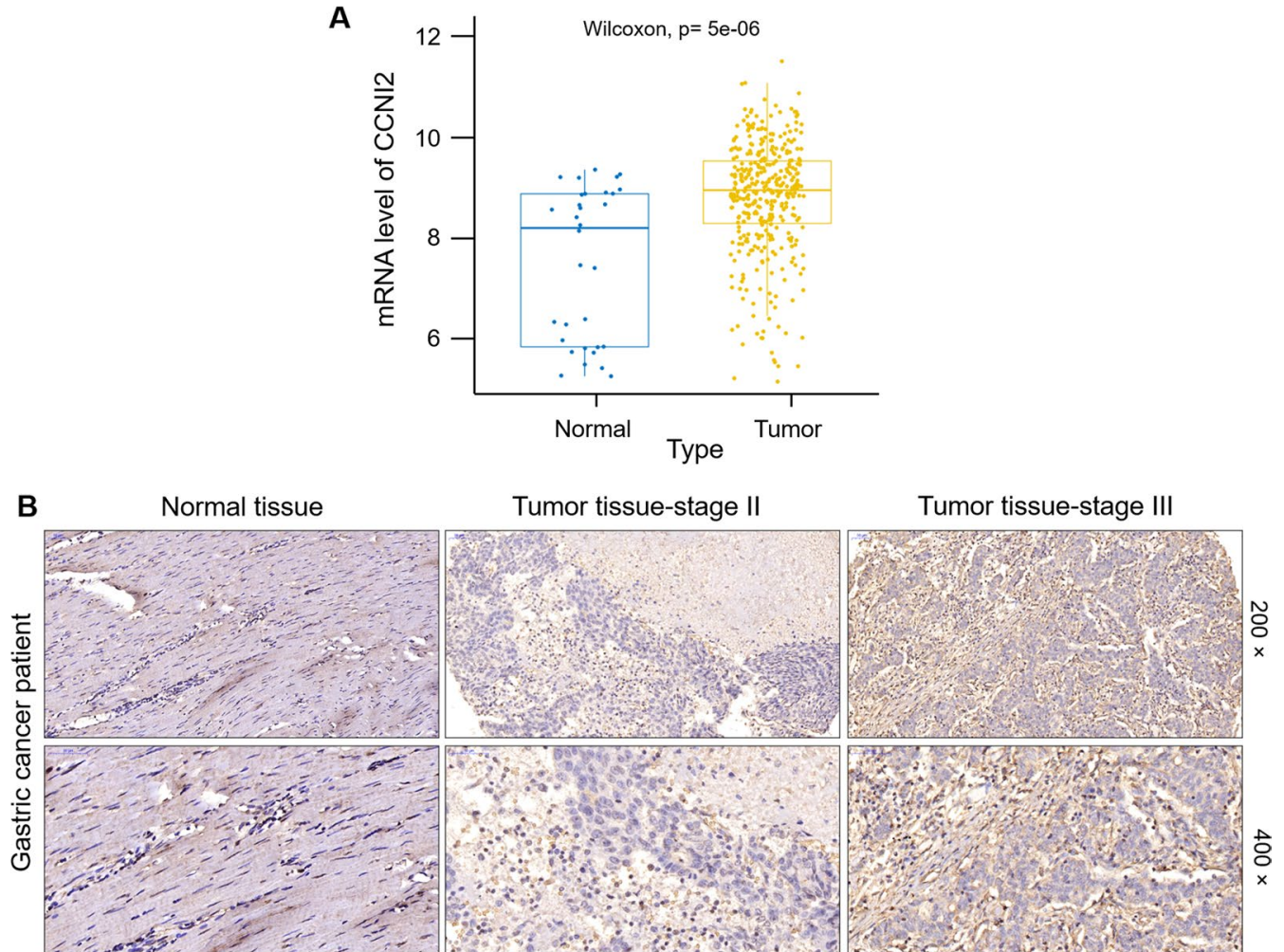

Fig. 1 CCNI2 expression is significantly elevated in human gastric cancer. A The expression profile of CCNI2 in 407 gastric cancer samples was analyzed based on The Cancer Genome Atlas (TCGA) database. B The expression level of CCNI2 in gastric cancer was determined by immunohistochemical staining and representative images were shown. Magnification is 200 and 400

Table 1 Expression patterns in gastric cancer tissues and paracarcinoma tissues revealed in immunohistochemistry analysis

\begin{tabular}{|c|c|c|c|c|c|}
\hline \multirow{2}{*}{$\begin{array}{l}\text { CCNI2 } \\
\text { expression }\end{array}$} & \multicolumn{2}{|c|}{ Tumor tissue } & \multicolumn{2}{|c|}{ Para-carcinoma tissue } & \multirow[t]{2}{*}{$p$ value } \\
\hline & Cases & $\begin{array}{l}\text { Percentage } \\
\text { (\%) }\end{array}$ & Cases & $\begin{array}{l}\text { Percentage } \\
\text { (\%) }\end{array}$ & \\
\hline Low & 50 & 53.8 & 101 & 100 & $<0.001$ \\
\hline High & 43 & 46.2 & 0 & - & \\
\hline
\end{tabular}

downregulated (Additional file 1: Fig. S2A). After CCNI2 expression was reduced, the number of migrating cells was significantly reduced (Fig. 2D). As showed in Fig. 2E, the migration ability of BGC-823 and SGC-7901 with reduced CCNI2 expression was significantly inhibited. Additionally, western blot results showed that CCNI2 knockdown reduced AKT phosphorylation level, downregulated CCND1 and CDK1, and upregulated MAPK9 expression (Additional file 1: Fig. S2B). These results suggested that CCNI2 knockdown slowed the progression of gastric cancer by inhibiting tumor cell proliferation and migration.

\section{Downregulation of CCNI2 suppressed tumor growth in the mouse xenograft model}

Mice xenograft models were established in 4-week-old nude mice by injection of CCNI2-knockdown SGC-7901 cells and the tumorigenesis rate was $100 \%$ and $50 \%$ in shCtrl and shCCNI2 groups, respectively. As illustrated in Fig. 3A, the fluorescence intensity of shCCNI2 group was obviously weaker than that of shCtrl group, suggesting that CCNI2 knockdown inhibited tumor growth. The mice were monitored 26 days after tumor injection, the growth of tumors in shCCNI2 group almost stagnated, while the tumors in the shCtrl group grew rapidly. The largest tumor volume was only $18.23 \mathrm{~mm}^{3}$ in the shCCNI2 group and $1306.39 \mathrm{~mm}^{3}$ in the shCtrl group (Fig. 3B). Subsequently, the two groups of tumors were weighed. The average weight of the shCCNI2 group $(0.012 \pm 0.013 \mathrm{~g})$ was significantly lower than that of the shCtrl group ( $1.011 \pm 0.329 \mathrm{~g})$ (Fig. 3C, D). Not surprisingly, the expression of proliferation-related ki67 in mouse tumor tissues showed that the signal of shCCNI2 was weaker than that of shCtrl group (Fig. 3E). Therefore, inhibition of CCNI2 repressed tumor growth in the mouse xenograft model. 
Table 2 Relationship between CCNI2 expression and tumor characteristics in patients with gastric cancer

\begin{tabular}{|c|c|c|c|c|}
\hline \multirow[t]{2}{*}{ Features } & \multirow[t]{2}{*}{ No. of patients } & \multicolumn{2}{|c|}{$\begin{array}{l}\text { CCNI2 } \\
\text { expression }\end{array}$} & \multirow[t]{2}{*}{$\mathrm{p}$ value } \\
\hline & & Low & High & \\
\hline All patients & 93 & 50 & 43 & \\
\hline Age (years) & & & & 0.331 \\
\hline$<64$ & 44 & 26 & 18 & \\
\hline$\geq 64$ & 49 & 24 & 25 & \\
\hline Gender & & & & 0.465 \\
\hline Male & 62 & 35 & 27 & \\
\hline Female & 31 & 15 & 16 & \\
\hline TInfiltrate & & & & 0.201 \\
\hline $\mathrm{T} 1$ & 6 & 4 & 2 & \\
\hline $\mathrm{T} 2$ & 12 & 9 & 3 & \\
\hline T3 & 55 & 27 & 28 & \\
\hline T4 & 20 & 10 & 10 & \\
\hline Lymphatic metastasis (N) & & & & 0.475 \\
\hline No & 14 & 12 & 2 & \\
\hline N1 & 14 & 6 & 8 & \\
\hline N2 & 20 & 7 & 13 & \\
\hline N3 & 45 & 25 & 20 & \\
\hline Stage & & & & 0.020 \\
\hline 1 & 5 & 4 & 1 & \\
\hline$\|$ & 22 & 17 & 5 & \\
\hline III & 63 & 26 & 37 & \\
\hline IV & 3 & 3 & 0 & \\
\hline Tumor size & & & & 0.960 \\
\hline$<5 \mathrm{~cm}$ & 38 & 20 & 18 & \\
\hline$\geq 5 \mathrm{~cm}$ & 48 & 25 & 23 & \\
\hline Lymph node positive & & & & 0.911 \\
\hline$\leq 6$ & 47 & 25 & 22 & \\
\hline$>6$ & 46 & 25 & 21 & \\
\hline Vessel carcinoma embolus & & & & 0.879 \\
\hline 0 & 15 & 8 & 7 & \\
\hline 1 & 54 & 30 & 24 & \\
\hline Nerve tumor infiltrates & & & & 0.884 \\
\hline 0 & 21 & 10 & 11 & \\
\hline 1 & 18 & 9 & 9 & \\
\hline Expression of CD34 & & & & 0.888 \\
\hline No & 10 & 6 & 4 & \\
\hline Yes & 32 & 20 & 12 & \\
\hline Expression of EGFR & & & & 0.274 \\
\hline No & 69 & 38 & 31 & \\
\hline Yes & 13 & 5 & 8 & \\
\hline Expression of VEGF & & & & $0.025^{*}$ \\
\hline No & 39 & 26 & 13 & \\
\hline Yes & 43 & 18 & 25 & \\
\hline Expression of CDX2 & & & & 0.202 \\
\hline No & 11 & 8 & 3 & \\
\hline Yes & 73 & 38 & 35 & \\
\hline Expression of Her2 & & & & 0.316 \\
\hline
\end{tabular}

Table 2 (continued)

\begin{tabular}{lllll}
\hline Features & No. of patients & \multicolumn{2}{l}{$\begin{array}{l}\text { CCNI2 } \\
\text { expression }\end{array}$} & p value \\
\cline { 3 - 4 } & & Low & High & \\
\hline No & 64 & 32 & 32 \\
Yes & 19 & 12 & 7 \\
\hline
\end{tabular}

Table 3 Relationship between CCNI2 expression and tumor characteristics in patients with gastric cancer

\begin{tabular}{|c|c|c|}
\hline & & CCNI2 \\
\hline \multirow[t]{3}{*}{ Stage } & & Pearson correlation 0.242 \\
\hline & & Significance (double-tailed) 0.020 \\
\hline & N & 93 \\
\hline
\end{tabular}

\section{HDGF was the downstream target of CCNI2 in gastric} cancer cells

In order to clarify the role of CCNI2 in gastric cancer, its potential mechanism was initially explored. RNA sequencing results showed that CCNI2 knockdown resulted in abnormal expression of DEGs, of which 1157 genes were upregulated and 1303 genes were downregulated. Figure $4 \mathrm{~A}$ is a heat map of hierarchical clustering of shCCNI2 and shCtrl two samples using |Fold Change $\mid \geq 1.3$ and FDR $<0.05$ as standard screening of differential gene expression profiles. Additionally, the interaction network between CCNI2 and DEGs was further analyzed based on IPA (Additional file 1: Fig. S3). The most significant DEGs were screened by PCR (Fig. 4B) and western blot (Fig. 4C), the results indicated that HDGF was downregulated after CCNI2 knockdown in SGC-7901 cells. Additionally, Pearson correlation analysis indicated a significant positive correlation between CCNI2 and HDGF expression (Fig. 4D). As illustrated in Fig. 4E, the Co-IP assay validated that there was protein interaction between CCNI2 and HDGF in SGC-7901 cells. Therefore, we preliminarily determined that HDGF was regulated by $\mathrm{CCNI} 2$ in gastric cancer and may be a downstream target of CCNI2.

\section{Knockdown of CCNI2 alleviates the promoting effects of HDGF overexpression in gastric cancer cells}

Since there was a relationship between CCNI2 and HDGF, their biological functions in gastric cancer cell lines deserved further investigation. SGC-7901 cells with high expression of HDGF were used to reveal the alterations of biological phenotypes. As showed in Fig. 5A, SGC-7901 cells with high HDGF expression showed a proliferation promoting effect. Meanwhile, the high expression of HDGF produced larger and more cell 


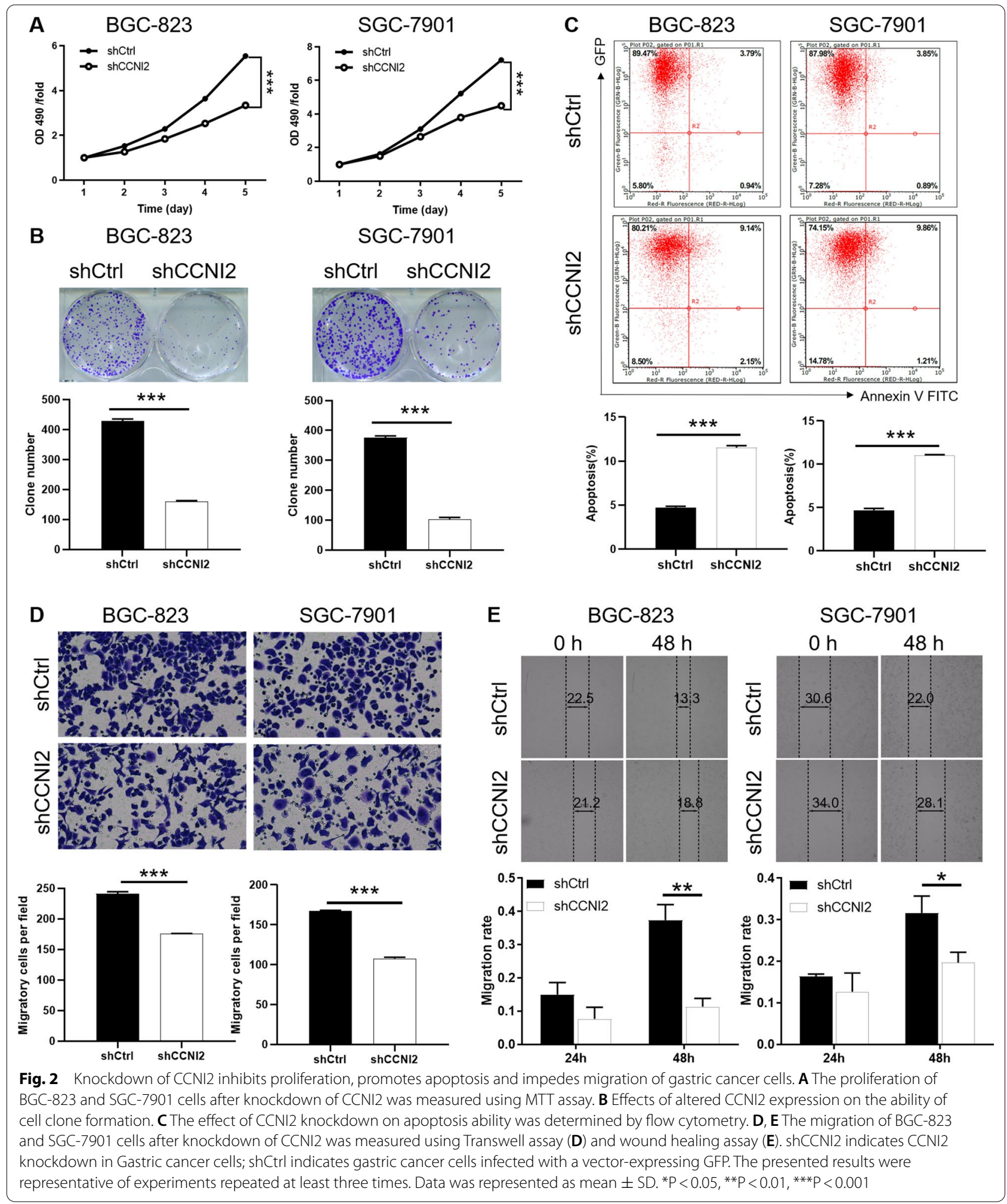

clones compared with the control group (Fig. 5B). Moreover, the apoptotic ability of SGC-7901 cells with high HDGF expression was reduced (Fig. 5C). The migration ability of SGC-7901 cells with HDGF overexpression was stronger than that of the control group (Fig. 5D, E). As a consequence, we clarified that HDGF can promote the 


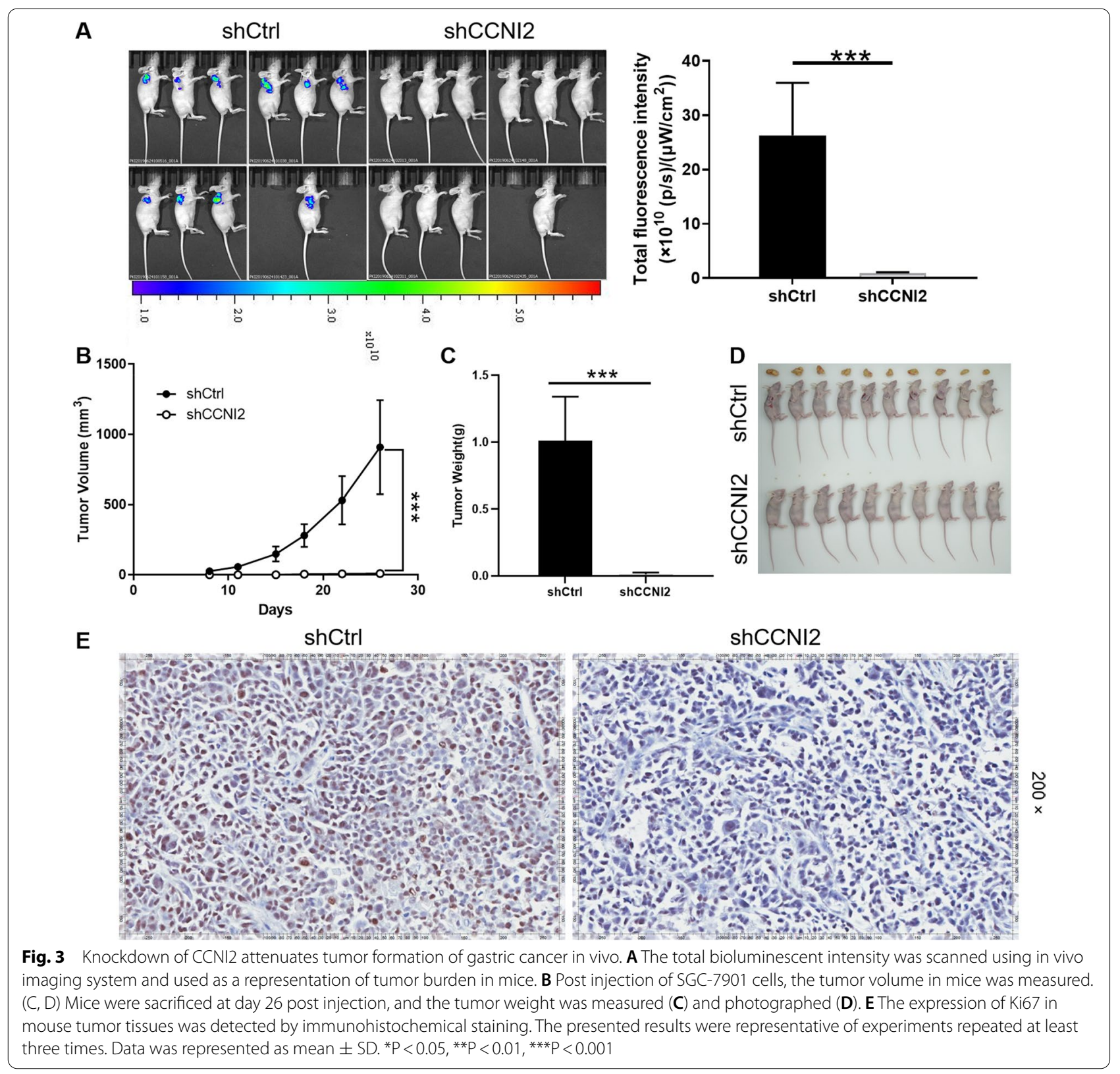

malignant progression of gastric cancer. Furthermore, the SGC-7901 cells with both CCNI2 downregulation and HDGF upregulation (shCCNI2+ HDGF) were established. Interestingly, shCCNI2+HDGF group could slow down the malignant progression of HDGF overexpression group in SGC-7901 cells, which was characterized by reducing proliferation (Fig. 5A), forming fewer clones (Fig. 5B), increasing apoptosis (Fig. 5C) and inhibiting migration (Fig. 5D, E). Taken together, the loss/gain-offunction assays demonstrated that knockdown of CCNI2 could alleviate the promoting effects of HDGF overexpression in SGC-7901 cells.

\section{Discussion}

In view of the fact that gastric cancer is a multi-stage disease process, characterized by the gradual development of various gene expression mutations and epigenetic alterations [2]. A major breakthrough of this study is the identification of promoting effect of CCNI2 in human gastric cancer. We found that CCNI2 was abundantly expressed in gastric cancer and was positively correlated with pathological stage. Additionally, inhibition of CCNI2 can slow down the malignant progression of gastric cancer by inhibiting tumor cell proliferation, increasing the susceptibility to apoptosis and suppressing migration. 


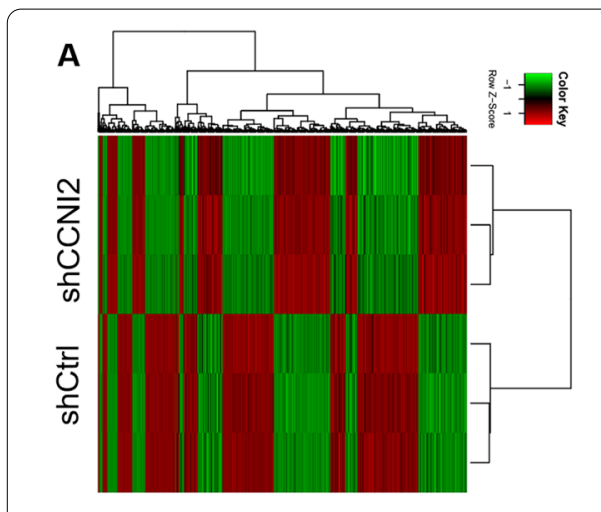

B
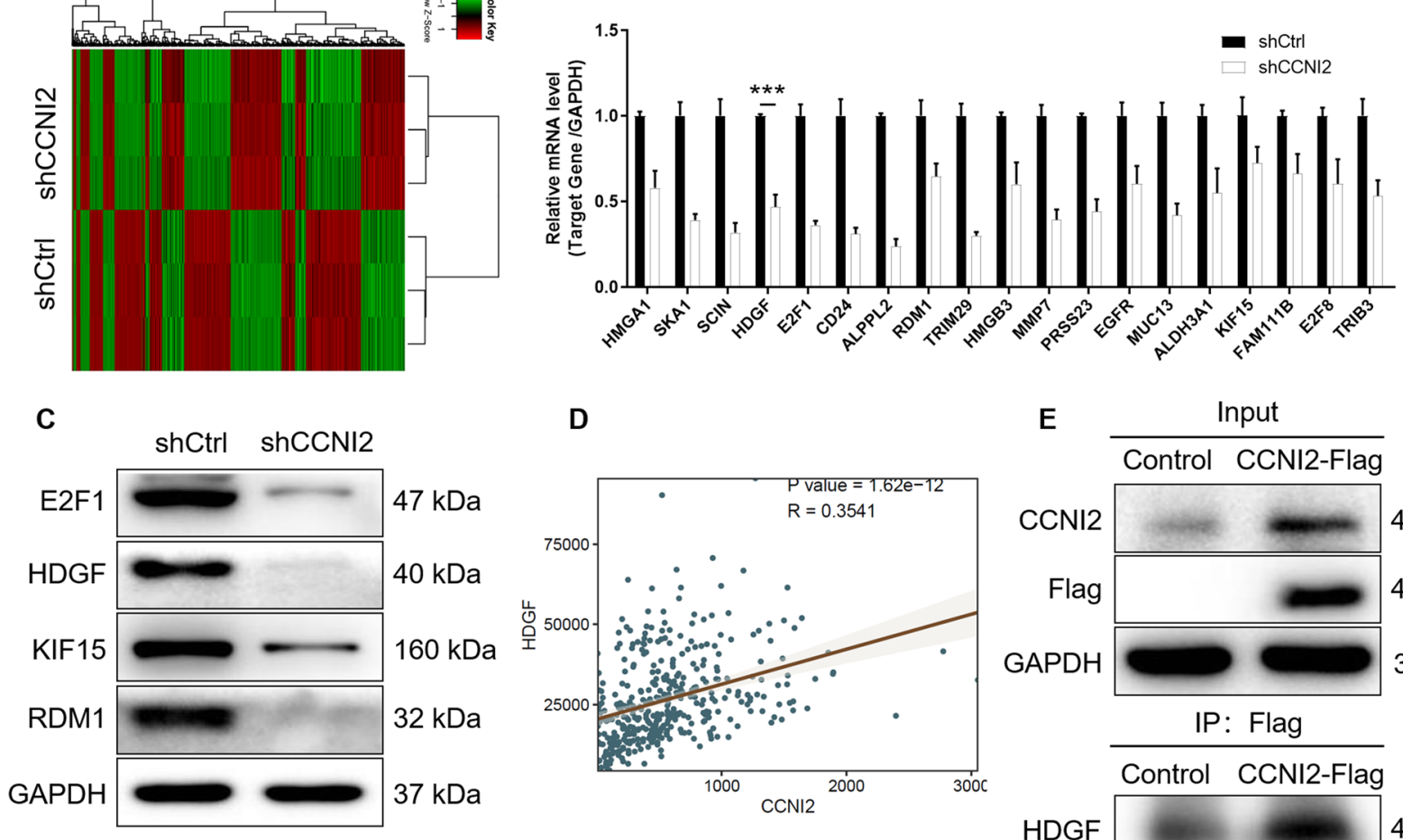

D
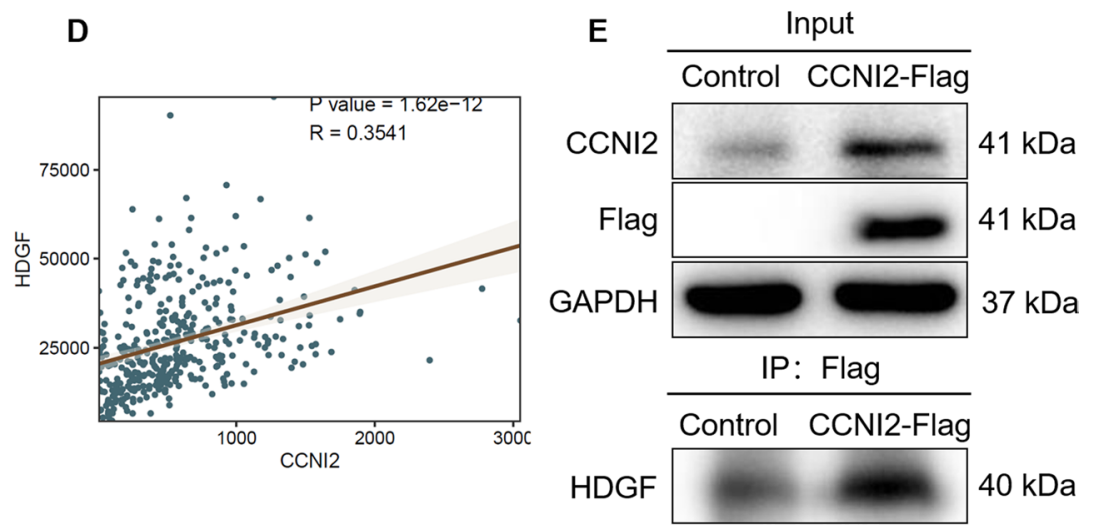

Fig. 4 Knockdown of CCNI2 results in the alteration of downstream proteins. A The DEGs between shCCNI2 and shCtrl groups of SGC-7901cells was identified. In the heat map of cluster analysis, each column represents a sample and each row represents a differential gene. The red indicates that the gene expression is upregulated, the green indicates that the gene expression is downregulated, the black indicates that the gene expression is not significantly changed, and the gray indicates that the signal strength of the gene is not detected. B, C The expression of several selected DEGs of SGC-7901 cells after knockdown of CCNI2 was measured by qPCR (B) and western blot (C). D Pearson correlation analysis indicated a significant positive correlation between CCNI2 and HDGF expression. E Proteins interaction between CCNI2 and CDK1 was determined by Co-IP assay. The presented results were representative of experiments repeated at least three times. Data was represented as mean $\pm S D$. ${ }^{*}<<0.05$, ${ }^{* * P}<0.01,{ }^{* * * P}<0.001$

The malignant transformation of normal cells is caused in part by aberrant gene expression disrupting the regulation of cell proliferation, senescence and apoptosis [23]. Previous study clarified those alterations in apoptosis were usually related to the occurrence and development of tumors, involving a series of cell signals [24]. The present study revealed that knockdown of CCNI2 in BGC-823 cells upregulated the expression of cytoC (cytochrome c), Bad (Bcl-2 antagonist of cell death), and BID. On the contrary, the expression levels of HSP60 (heat shock protein 60), IGF-II (Insulin-like growth factor II), and sTNF-R1 (tumor necrosis factor (TNF) and its soluble receptors type 1) were downregulated. Apoptosis is performed by caspases, a subfamily of cysteine proteases. One of the main caspase activation pathways is the activation of cytoC, which in turn induces a series of biochemical reactions, leading to caspase activation and subsequent cell death [25]. Pro-apoptotic factor Badmediated apoptotic pathway was associated with human cancer development [26]. Bid is an abundant pro-apoptotic protein of the Bcl-2 family that is crucial for death receptor-mediated apoptosis in many cell systems [27]. Furthermore, the reduction of HSP60 expression can lead to cell apoptosis, which plays a key regulatory role in cell apoptosis [28]. IGF-II is an anti-apoptotic protein, which is highly expressed in $\beta$ cells during development and stimulates cell survival and proliferation [29]. sTNFR1 as a key mediator between apoptosis and cancer cell progression [30]. On this basis, the alterations in key apoptotic factors after CCNI2 knockdown were consistent with the apoptotic phenotypes of gastric cancer cells. However, the molecular mechanism that CCNI2 regulated apoptosis in gastric cancer need more exploration.

Studies have shown that phosphatidylinositol 3-kinase (PI3K)/AKT signaling pathway is involved in a variety of carcinogenic processes, including cell proliferation, growth, survival, apoptosis and migration [31]. CCND1 (Cyclin D1) overexpression correlated with poor tumor 


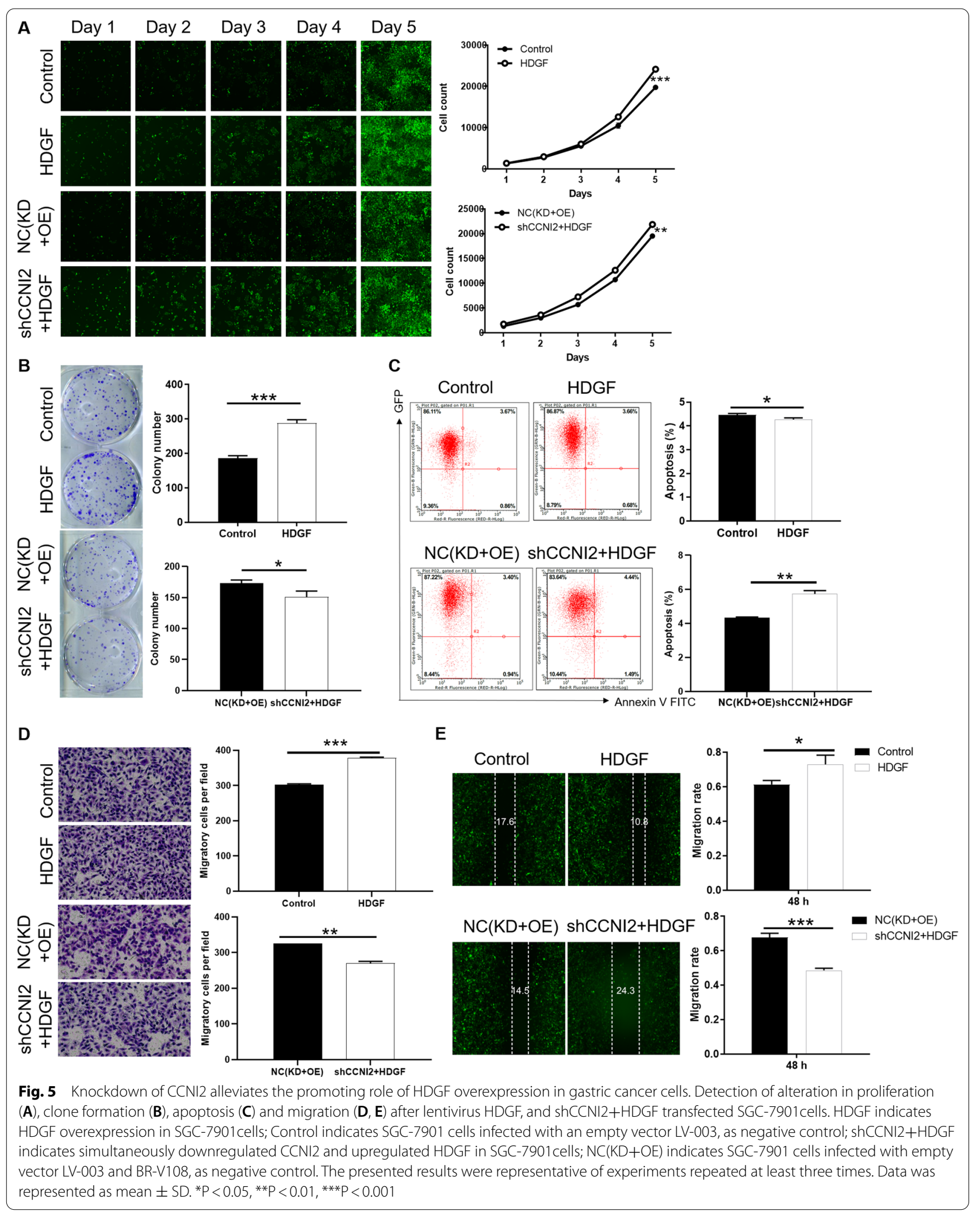


differentiation and prognosis in gastric cancer [32]. In this study, western blot analysis found that CCNI2 knockdown resulted in reduced AKT phosphorylation level, downregulated CCND1 and CDK1, upregulated MAPK9 expression in gastric cancer cells.

Additionally, we studied the regulation mechanism of CCNI2 on gastric cancer and found that HDGF may be the downstream of CCNI2. Transcription factor hepatoma-derived growth factor (HDGF) is an acidic heparin-binding growth factor, originally isolated from the culture medium of human hepatocellular carcinoma cell line HuH-7 [33]. Previous studies have shown that HDGF can be translocated into the nucleus and act as a direct DNA-binding protein, possibly as both cytokine and transcription factor [34-37]. HDGF is endogenously expressed in endothelial cells and can induce exogenous angiogenesis [38]. Moreover, HDGF plays an important role in cell cycle, apoptosis, cytokine signal transduction and metabolism of embryonic stem cells [39]. HDGF is involved in tumor-related events such as tumorigenesis, metastasis, and angiogenesis [40]. For instance, HDGF promotes growth and metastasis of hepatocellular carcinoma cells [41]. Studies have shown that glioblastoma stem cell-like cells can express HDGF to directly induce tumor angiogenesis [42]. In addition, downregulation of HDGF inhibits the tumorigenesis of bladder cancer cells by inactivating the PI3K/AKT signaling pathway [43]. Importantly, HDGF participates in Helicobacter Pylori-induced neutrophils recruitment, gastritis and gastric carcinogenesis [44].

\section{Conclusions}

Our study found that HDGF overexpression exhibited a significant promotion in the progression of gastric cancer cells. Besides, knockdown of CCNI2 could alleviate the promoting role of HDGF overexpression in gastric cancer cells. Thus, CCNI2 promote the development and progression of gastric cancer through HDGF, which may be a therapeutic target for gastric cancer.

\section{Supplementary Information}

The online version contains supplementary material available at https://doi. org/10.1186/s12935-021-02352-6.

Additional file 1. Additional figures and tables.

\section{Acknowledgements}

Not applicable.

\section{Authors' contributions}

The project design was completed by GW and WC. The operation experiment was carried out by WC and YZ. Data analysis for YZ. WC finished writing the manuscript. Data review and article review by PS. All authors read and approved the final manuscript.
Funding

Natural science foundation of Henan province (No. 162300410292); Launch fund of academician workstation of Henan province for non-coding nucleic acid transformation research.

\section{Availability of data and materials}

All data generated or analysed during this study are included in this published article and its additional files.

\section{Declarations}

Ethics approval and consent to participate

The experimental procedures performed on the mice were approved by the Ethics Committee of Henan Provincial People's Hospital.

\section{Consent for publication}

Not applicable.

\section{Competing interests}

The authors declare that they have no competing interests.

Received: 13 Auqust 2021 Accepted: 19 November 2021

Published online: 11 December 2021

\section{References}

1. Gao JP, Xu W, Liu WT, Yan M, Zhu ZG. Tumor heterogeneity of gastric cancer: From the perspective of tumor-initiating cell. World J Gastroenterol. 2018;24(24):2567-81.

2. Smyth EC, Nilsson M, Grabsch HI, van Grieken NC, Lordick F. Gastric cancer. Lancet. 2020;396(10251):635-48.

3. Machlowska J, Baj J, Sitarz M, Maciejewski R, Sitarz R. Gastric cancer: epidemiology, risk factors, classification, genomic characteristics and treatment strategies. Int J Mol Sci. 2020;21:11.

4. Eusebi LH, Telese A, Marasco G, Bazzoli F, Zagari RM. Gastric cancer prevention strategies: a global perspective. J Gastroenterol Hepatol. 2020;35(9):1495-502.

5. Biagioni A, Skalamera I, Peri S, Schiavone N, Cianchi F, Giommoni E, et al. Update on gastric cancer treatments and gene therapies. Cancer Metastasis Rev. 2019:38(3):537-48.

6. Bang YJ, Van Cutsem E, Feyereislova A, Chung HC, Shen L, Sawaki A, et al. Trastuzumab in combination with chemotherapy versus chemotherapy alone for treatment of HER2-positive advanced gastric or gastrooesophageal junction cancer (ToGA): a phase 3, open-label, randomised controlled trial. Lancet. 2010;376(9742):687-97.

7. Khan U, Shah MA. Ramucirumab for the treatment of gastric or gastroesophageal junction cancer. Expert Opin Biol Ther. 2019:19(11):1135-41.

8. Fukuoka S, Hara H, Takahashi N, Kojima T, Kawazoe A, Asayama M, et al. Regorafenib Plus Nivolumab in Patients With Advanced Gastric or Colorectal Cancer: An Open-Label, Dose-Escalation, and Dose-Expansion Phase Ib Trial (REGONIVO, EPOC1603). J Clin Oncol. 2020;38(18):2053-61.

9. Shitara K, Ozguroglu M, Bang YJ, Di Bartolomeo M, Mandala M, Ryu $\mathrm{MH}$, et al. Pembrolizumab versus paclitaxel for previously treated, advanced gastric or gastro-oesophageal junction cancer (KEYNOTE-061): a randomised, open-label, controlled, phase 3 trial. Lancet. 2018;392(10142):123-33.

10. Su SC, Tsai LH. Cyclin-dependent kinases in brain development and disease. Annu Rev Cell Dev Biol. 2011:27:465-91.

11. Lopes JP, Agostinho P. Cdk5: multitasking between physiological and pathological conditions. Prog Neurobiol. 2011;94(1):49-63.

12. Liu C, Zhai X, Zhao B, Wang Y, Xu Z. Erratum: Cyclin I-like (CCNI2) is a cyclin-dependent kinase 5 (CDK5) activator and is involved in cell cycle regulation. Sci Rep. 2017;7:44164.

13. Malumbres M. Cyclin-dependent kinases. Genome Biol. 2014;15(6):122.

14. Liu W, Li J, Song YS, Li Y, Jia YH, Zhao HD. Cdk5 links with DNA damage response and cancer. Mol Cancer. 2017;16(1):60.

15. Pozo K, Bibb JA. The Emerging Role of C $\mathrm{dk} 5$ in Cancer. Trends Cancer. 2016;2(10):606-18. 
16. Liu C, Zhai X, Zhao B, Wang Y, Xu Z. Cyclin I-like (CCNI2) is a cyclindependent kinase 5 (CDK5) activator and is involved in cell cycle regulation. Sci Rep. 2017;7:40979.

17. Lai DM, Bi JJ, Chen YH, Wu YD, Huang QW, Li HJ, et al. CCNI2 plays a promoting role in the progression of colorectal cancer. Cancer Med. 2021;10(6):1913-24.

18. Cai XZ, Huang WY, Qiao Y, Du SY, Chen Y, Chen D, et al. Inhibitory effects of curcumin on gastric cancer cells: a proteomic study of molecular targets. Phytomedicine. 2013:20(6):495-505.

19. Koo M, Squires JM, Ying D, Huang J. Making a Tissue Microarray. Methods Mol Biol. 2019;1897:313-23.

20. Shiraki Y, Mii S, Enomoto A, Momota H, Han YP, Kato T, et al. Significance of perivascular tumour cells defined by CD109 expression in progression of glioma. J Pathol. 2017;243(4):468-80.

21. Ratti C, Minguzzi S, Turina M. A Rapid Protocol of Crude RNA/DNA Extraction for RT-qPCR Detection and Quantification. Methods Mol Biol. 2019;1875:159-69.

22. Martinotti S, Ranzato E. Scratch Wound Healing Assay. Methods Mol Biol. 2020;2109:225-9.

23. Balani S, Nguyen LV, Eaves CJ. Modeling the process of human tumorigenesis. Nat Commun. 2017;8:15422.

24. Pistritto G, Trisciuoglio D, Ceci C, Garufi A, D’Orazi G. Apoptosis as anticancer mechanism: function and dysfunction of its modulators and targeted therapeutic strategies. Aging (Albany NY). 2016;8(4):603-19.

25. Jiang $X$, Wang $X$. Cytochrome C-mediated apoptosis. Annu Rev Biochem. 2004;73:87-106.

26. Stickles XB, Marchion DC, Bicaku E, Al Sawah E, Abbasi F, Xiong Y, et al. BAD-mediated apoptotic pathway is associated with human cancer development. Int J Mol Med. 2015;35(4):1081-7.

27. Esposti MD. The roles of Bid. Apoptosis. 2002;7(5):433-40.

28. Gupta S, Knowlton AA. HSP60, Bax, apoptosis and the heart. J Cell Mol Med. 2005;9(1):51-8.

29. Hong J, Zhang G, Dong F, Rechler MM. Insulin-like growth factor (IGF)binding protein-3 mutants that do not bind IGF-I or IGF-II stimulate apoptosis in human prostate cancer cells. J Biol Chem. 2002;277(12):10489-97.

30. Mielczarek-Palacz A, Kondera-Anasz Z, Sikora J. Higher serum levels of tumour necrosis factor and its soluble receptors are associated with ovarian tumours. Arch Med Sci. 2012;8(5):848-53.

31. Murugan AK. Special issue: PI3K/Akt signaling in human cancer. Semin Cancer Biol. 2019;59:1-2.

32. Shan YS, Hsu HP, Lai MD, Hung YH, Wang CY, Yen MC, et al. Cyclin D1 overexpression correlates with poor tumor differentiation and prognosis in gastric cancer. Oncol Lett. 2017;14(4):4517-26.

33. Nakamura H, Izumoto $Y$, Kambe H, Kuroda T, Mori T, Kawamura K, et al. Molecular cloning of complementary DNA for a novel human hepatoma-derived growth factor. Its homology with high mobility group-1 protein. J Biol Chem. 1994;269(40):25143-9.

34. Everett AD, Stoops T, McNamara CA. Nuclear targeting is required for hepatoma-derived growth factor-stimulated mitogenesis in vascular smooth muscle cells. J Biol Chem. 2001;276(40):37564-8.

35. Kishima $Y$, Yamamoto $H$, Izumoto $Y$, Yoshida $K$, Enomoto $H$, Yamamoto $\mathrm{M}$, et al. Hepatoma-derived growth factor stimulates cell growth after translocation to the nucleus by nuclear localization signals. J Biol Chem. 2002:277(12):10315-22.

36. Nameki N, Tochio N, Koshiba S, Inoue M, Yabuki T, Aoki M, et al. Solution structure of the PWWP domain of the hepatoma-derived growth factor family. Protein Sci. 2005;14(3):756-64.

37. Yang J, Everett AD. Hepatoma-derived growth factor binds DNA through the N-terminal PWWP domain. BMC Mol Biol. 2007;8:101.

38. Everett AD, Narron JV, Stoops T, Nakamura H, Tucker A. Hepatoma-derived growth factor is a pulmonary endothelial cell-expressed angiogenic factor. Am J Physiol Lung Cell Mol Physiol. 2004;286(6):L1194-201.

39. Yang Y, Li H, Zhang F, Shi H, Zhen T, Dai S, et al. Clinical and biological significance of hepatoma-derived growth factor in Ewing's sarcoma. J Pathol. 2013:231(3):323-34.

40. Bao C, Wang J, Ma W, Wang X, Cheng Y. HDGF: a novel jack-of-all-trades in cancer. Future Oncol. 2014;10(16):2675-85.

41. Yang GY, Zhang AQ, Wang J, Li CH, Wang XQ, Pan K, et al. Hepatomaderived growth factor promotes growth and metastasis of hepatocellular carcinoma cells. Cell Biochem Funct. 2016;34(4):274-85.

42. Thirant C, Galan-Moya EM, Dubois LG, Pinte S, Chafey P, Broussard C, et al. Differential proteomic analysis of human glioblastoma and neural stem cells reveals HDGF as a novel angiogenic secreted factor. Stem Cells. 2012;30(5):845-53.

43. Zhang C, Chang X, Chen D, Yang F, Li Z, Li D, et al. Downregulation of HDGF inhibits the tumorigenesis of bladder cancer cells by inactivating the PI3K-AKT signaling pathway. Cancer Manag Res. 2019;11:7909-23.

44. Chu TH, Huang ST, Yang SF, Li CJ, Lin HW, Weng BC, et al. Hepatomaderived growth factor participates in Helicobacter Pylori-induced neutrophils recruitment, gastritis and gastric carcinogenesis. Oncogene. 2019:38(37):6461-77.

\section{Publisher's Note}

Springer Nature remains neutral with regard to jurisdictional claims in published maps and institutional affiliations.
Ready to submit your research? Choose BMC and benefit from:

- fast, convenient online submission

- thorough peer review by experienced researchers in your field

- rapid publication on acceptance

- support for research data, including large and complex data types

- gold Open Access which fosters wider collaboration and increased citations

- maximum visibility for your research: over 100M website views per year

At $\mathrm{BMC}$, research is always in progress.

Learn more biomedcentral.com/submissions 